\title{
De tumba a útero
}

\section{Amalia GONZÁLEZ SUÁREZ}

\author{
IES Padre Feijoo de Gijón \\ amaliags@hotmail.es
}

Recibido: Mayo 2015

Aceptado: Junio 2015

\section{RESUMEN}

En el trabajo ensayamos un diálogo entre dos contextos distantes cronológicamente: Platón y el tiempo presente. El tema a confrontar es la diferencia entre sexos en lo relativo a la reproducción. Platón consideró irrelevante esta diferencia en el diálogo República y a continuación la convirtió en uno de los centros de su legislación, en un verdadero asunto de estado. En la actualidad, el uso creciente de la maternidad subrogada, que convierte la gestación en un proceso del que se puede prescindir contratándola con otra mujer, nos exige una reflexión sobre el significado político que le otorgamos a tal práctica y, por ende, el marco legislativo en el que la encuadramos.

Palabras clave: Platón, subrogación, cuerpo, mujeres.

\section{Tomb is becaming womb}

\begin{abstract}
In this paper we rehearsed dialogue between two chronologically distant contexts: Plato and the present time. The issue to confront is the difference between the sexes in terms of reproduction. Plato considered irrelevant the difference in the dialogue Republic and then became one of the centers of their legislation, in a real matter of state. Currently, the increasing use of surrogacy, which makes pregnancy in a process that can be dispensed by contracting with another woman, it demands a reflection on the political significance that we attach to this practice and thus the legislative framework in which we frame it.
\end{abstract}

Key words: Plato, subrogation, body, women.

\section{SOLO ES RIDÍCULO EL MAL}

Sócrates pronuncia esta frase en la República de Platón (452 c), para añadir que "lo provechoso es bello y lo pernicioso feo". El mal es ridículo, pernicioso y feo. El filósofo hilvana estos tres conceptos abstractos para defender que las mujeres tienen 
tanta capacidad como los varones para gobernar ${ }^{1}$, y afrontar las implicaciones que esto conlleva: que las mujeres se preparen para ello y hagan gimnasia lo mismo que los varones. Hacer gimnasia ${ }^{2}$, implicaba la desnudez, por tanto, Platón tiene que vérselas con la imagen de las mujeres de cualquier edad haciendo ejercicio desnudas. Que las mujeres viejas hagan gimnasia, puede mover a risa ${ }^{3}$, y, por ende, no ser tomadas en serio. Pero Platón remata: la verdadera vestimenta es la de la excelencia.

En el mundo griego, especialmente en Atenas (Iriarte y González, 2008: 196199), la desnudez representaba lo civilizado, frente a lo bárbaro que era lo vestido. El varón civilizado se presentaba desnudo, mientras que las mujeres se presentaban vestidas, salvo las escandalosas espartanas. Reían los griegos de los persas, porque estos andaban con muchos ropajes. Así, la desnudez de las mujeres sería un intento civilizatorio, no una objetualización o cosificación como en la sociedad actual. Más que una naturalización o animalización era una desnaturalización o desbiologización: [Habituada la espartana] “a mostrar su cuerpo con soltura, la espartana desnuda su mente con la misma naturalidad exponiendo ante la colectividad su opinión sobre los asuntos más trascendentales para el bien común de su polis” (Iriarte y González, 2008: 197).

La desnudez de los varones era habitual. Se impuso como norma en los juegos olímpicos, pero no todas las ciudades griegas tenían el mismo atrevimiento al mostrarse sin vestimenta. La población espartana era más atrevida y escandalizaba a las de otras ciudades, puesto que las leyes permitían que las mujeres participasen desnudas o casi desnudas (Clark, K. 1981:80).

En el diálogo República, ya mencionado, Sócrates se ocupa de convencer a Adimanto sobre la conveniencia de que las mujeres se entrenen, pues ya ha quedado sentado que deben ser guerreras y, si esto es así, han de prepararse para ello. No hay más remedio que ser consecuente.

Las jóvenes, pase, pero las viejas, no; ya parecen ridículos los viejos arrugados ¿qué no van a parecer las viejas arrugadas? Platón no se arredra ante imágenes tan contundentes como la de una vieja desnuda haciendo entrenamiento guerrero, y confía en que la pedagogía ponga fin a la visión de la desnudez como motivo de risa, puesto que "a los griegos - como ahora a los bárbaros- les parecía vergonzoso y ridículo mirar a hombres desnudos. Solo cuando empezaron a hacer ejercicios gimnásticos los cretenses primeramente y después los lacedemonios, les fue posible a los chistosos de entonces ridiculizar estas cosas" (República 452 c-d). Solamente los tontos, son quienes se quedarán con la ridiculez y la mera risa, pues estos no saben que el cuerpo es mero estorbo impuesto a las almas, que son las verdaderas importantes.

Vestimenta, barbarie y mujer eran tres esferas unidas en los griegos frente a

${ }^{1}$ Si bien añade que en todo son más débiles (asthenésteron.

${ }^{2}$ Gymnós, palabra de donde viene gimnasia, significa desnudo.

${ }^{3}$ Para to ethos geloia: ridículo debido a la costumbre. 
desnudez, civilización y varón (Iriarte y González, 2008: 204-205). De ahí, la risa que los persas provocaban en los griegos se debía a que se parecían a mujeres. Herodoto en IX, 20 relata cómo en algunos combates entre griegos y persas, los primeros no solo causaban daño físico a los segundos, sino también en su honor: "los tildaban de mujeres” puesto que

"Desde el punto de vista bélico, el imaginario griego -afectado, sin duda, por el impresionante desembarco de los cuerpos de arqueros persas en Maratón- asocia el ejército enemigo a la desmesura numérica, a la amenaza visual que supone el llamativo vestuario de sus guerreros [...]

En definitiva, la descripción del Otro por excelencia que, desde la perspectiva helena, es el persa, incide de forma crucial en la autodefinición que los griegos -por no decir los atenienses- se procuraron; es decir, en la imagen ideal que necesitaron tener de sí mismos [...] al plasmar la idea de que el desnudo masculino griego, lejos de simbolizar al "bárbaro", remite a la quintaesencia de lo "civilizado". (Iriarte y González, 2008: 202-203).

La preparación de las mujeres para la guerra es la exigencia lógica del argumento de Platón en su empeño de planificar una sociedad plenamente justa. Aquí la diferencia entre varón y mujer se reduce a una cuestión biológica: que el varón engendra y la mujer pare. Engendrar y parir nada tienen que ver con la capacidad de gobernar, nos dice el filósofo a través de su maestro, es una condición corporal sin importancia, análoga a tener o no tener pelo. Platón parece haber atemperado las afirmaciones de diálogos considerados inmediatamente anteriores a República en los que el cuerpo de varón o de mujer marcaba límites respecto a la capacidad de llegar a la sabiduría. En efecto, Platón que había contrapuesto el cuerpo de las mujeres al de los varones en Banquete y Fedro, representándolo como un mal o caída mayor para el caso de las almas, parece rescatarlo en la República donde la igualdad varones y mujeres debe imperar y está asociada a la disolución de la familia para las clases superiores y a que el estado subrogue ${ }^{4}$ la maternidad de estas clases superiores.

Mantiene Platón una diferencia entre los cuerpos de varón y de mujer en los diálogos, Banquete (181b-c, 191 d-192 a, 206 e, 208 e, 209 a-d) y Fedro (250 e) que no es irrelevante. Estos diálogos son anteriores a República y en ellos podemos leer que si bien todo cuerpo es estorbo, tumba y tira hacia abajo de las almas apartándolas de la posibilidad de contemplar las ideas, la diferencia entre cuerpo de varón y de mujer está en que el cuerpo de las mujeres tira más, y más hacia abajo. "El cuerpo es peso y el femenino peso extra" (Ibarra, 2011). El cuerpo le "corta las alas" al alma cuando de viajar al campo de las ideas se trata, de modo que si la caída es en cuerpo de mujer, el alma se estrella en el suelo, pues el cuerpo rige sobre el alma, y así en las mujeres la

${ }^{4}$ Si se permite el anacronismo. 
generación es del cuerpo y no del alma. Las mujeres dan a luz cuerpos, mientras que algunos varones dan a luz ideas; las primeras generan según el cuerpo y los segundos según el alma (Banquete 181b-c, 208e-209a, 191d-192a, Teeteto 149a-e, 173d-e). Algunos varones que se parecen a mujeres sienten más debilidad por generar según el cuerpo que según el alma y, por ello, se dirigen a las mujeres (González, 1999:95 y ss.).

Platón recrea los tiempos narrados por los mitos en los que la humanidad estaba formada exclusivamente por varones cuando en Banquete y Fedro describe el viaje del alma hacia la sabiduría, hacia el mundo de las ideas, siendo el cuerpo estorbo y el de las mujeres más. Pero cuando le toca disertar sobre la implantación práctica de la justicia, asunto del que se ocupa en República, el filósofo ha de defender el cuerpo de las mujeres de las risas.

Para esta defensa de los cuerpos fortalecidos de las mujeres y de su entrenamiento, Platón nos presenta a las mujeres lacedemonias, según hemos indicado anteriormente. Estas mismas mujeres lacedemonias son las recreadas por el comediógrafo Aristófanes para ridiculizar, por un lado, la insensatez de la guerra, o al menos el desmesurado tiempo que se prolonga, y, por el otro, a los malos gobiernos. El primer tema aparece tratado en Lisístrata, el segundo en Las Asambleístas. En ambas son las mujeres protagonistas y en ambas las relaciones sexuales son colocadas en el centro de la política. El discurso de Lisístrata es un discurso político,es la utilización de las relaciones sexuales como fuerza reivindicativa: las mujeres, cansadas de las calamidades de la guerra, se niegan a las relaciones sexuales con sus maridos para forzarlos a firmar la paz. En Lisístrata Aristófanes pone en boca de un grupo de mujeres dirigidas por Lisístrata un discurso contra la guerra: esta no deja de proporcionar desdichas y las mujeres civilizadas, que hacían gimnasia desnudas, oponen su civilización de paz a la civilización de guerra de los varones. En la otra comedia, Las Asambleístas, las mujeres se proponen como gobernantas ante los ineficaces gobiernos de los varones. Praxágora, la protagonista, presenta a las mujeres como mejores gobernantas, y promete abundancia de bienes y distribución por igual de ellos para el disfrute: mucho para todos. Nada parece más deseable que eso, abundancia para todos. Todo parece deseable y fácil, pues las mujeres se autodefinen como mejores gobernantas y mejores administradoras. Ahora bien, el principio de abundancia para todas y todos se quiebra cuando se ponen los bienes sexuales a la par de otros bienes como la comida. Hay una diferencia entre comida y sexo; la comida es necesaria y el sexo no; el sexo es deseo. El sexo no lo podemos desvincular del deseo y, por ende, su satisfacción no la podemos tramitar como obligación. Y esto es lo que ocurriría si se prescribiese abundancia sexual para todas y todos: viejas y viejos, cuerpos agradables y desagradables, tendrían derecho a las relaciones sexuales, de modo que habría que imponer a quienes desean que antes de cumplir su anhelo satisfagan el de quienes no tendrían oportunidad si no fuese bajo obligación. Entre los reclamos de abundancia está la sexual, y así quienes son viejas, deformes, en definitiva, poco apetecibles sexualmente, también tendrán derecho. Aquí se acaba la política de Praxágora, pues quienes más satisfacción obtendrían serán las personas poco agraciadas físicamente, como las ancianas, al tener asegurado uno de los bienes que, de otro modo, sería más incierto: la satisfacción del deseo sexual. Esto lo 
escenifica Aristófanes en una disputa ente una joven y una vieja que reclama acostarse con el joven antes de que este lo haga con la joven. Una especie de derecho de pernada de quienes son poco agraciados físicamente $\mathrm{y}$, por ende, apetecibles sexualmente (González, 1999: 73 y ss).

Esta situación ya la había previsto Blépiro, el esposo de Praxágora, quien se muestra dichoso al verse descargado de las tareas de participación política: se imagina una vida de holganza y felicidad; solo hasta que le asalta el temor de que el gobierno de las mujeres intervenga en lo relativo a la satisfacción de los deseos sexuales, y las mujeres impongan a los esposos satisfacer todos los deseos sexuales de ellas. Dato que atestigua que las relaciones más deseadas no eran, o no solo eran, las que tenían lugar entre esposos.

Situación inversa es la que el mismo autor nos describe en Lisístrata, aquí las mujeres abandonan el hogar y van al lugar sagrado de la Acrópolis, donde no es posible tener relaciones sexuales y deciden mantenerse allí, sometiendo a sus maridos a la abstinencia sexual, mientras no firmen la paz y se abstengan de guerrear. Quizá Platón viese esto ridículo, porque era el mal, porque se sometía a la ciudad y a la justicia a un vaivén de deseos. Esto sí que sería ridículo y movería a risa, por su conexión con el mal. No así que las mujeres se ejercitasen desnudas.

Escasez sexual o abundancia sexual parecen ser las alternativas que propone Aristófanes. Nada de ello parece ser conveniente, aunque si hay que apostar, parece desprenderse de la comedia, mejor la escasez, pues la abstinencia sexual abanderada por Lisístrata lleva a los varones a firmar la paz.

Lo mejor, parece decirnos Platón, es que no tenga que ser planteado el dilema entre mucho y poco sexo. Lo deseable es erradicar la pregunta. Eliminar el deseo o al menos desvincularlo del sexo. Platón desprecia el deseo sexual heterosexual a la hora de gobernar, porque está vinculado a la reproducción, según el cuerpo, y ésta no ha de ser un asunto particular, antes bien, es un asunto de estado. El gobernante controla los hogares y planifica las uniones de quienes deben procrear. Buen cuerpo es cuerpo sin deseo o que no cede al deseo. Porque el verdadero cuerpo es el cuerpo de la polis, donde el cuerpo particular no puede sentir particularmente, solo colectivamente: si la polis es como un cuerpo, los cuerpos particulares que forman parte de él, deben ser redefinidos en beneficio del conjunto: "lo mismo que cuando me duele un dedo, todo el cuerpo resulta afectado, cuando a alguien de la polis le pasa algo, ha de pasarle al resto" (República 462 c-d). Esto trae consigo la eliminación del deseo, pues no se puede decir que cuando alguien desea, desean todos, pues los deseos no pueden satisfacerse en su totalidad, debido a que son diferentes según personas, no así las necesidades que son las mismas. Los deseos introducen la disensión en el cuerpo político (González 1999: 148-151).

Las almas, según Platón son asexuadas, están libres del cuerpo. Lo que introduce el deseo es la unión con el cuerpo, pero decir no a este deseo es el empeño de quienes practican la filosofía. Vivir según la filosofía es un continuo separar el alma del cuerpo, separación que no es otra cosa que morir, había dicho Sócrates en el diálogo que mantiene con sus discípulos poco antes de ser ejecutado, según nos refleja Platón en Fedón. 
El maltrecho cuerpo de las mujeres que Platón describe en Banquete y Fedro, se rehabilita en la República al equipararlo al de los varones. Se equipara al de los varones declarando insignificante la diferencia en lo relativo a la reproducción. Aquí Platón ya no diferencia entre reproducción del alma y del cuerpo, solamente mira a la del cuerpo, porque la reproducción según el alma ya estaba hecha, ya nos había descrito Platón en diálogos anteriores, Banquete y Fedro principalmente, cómo los varones llegaban a la sabiduría, como daban a luz según el alma (González, 1999: 95 y ss.). La reproducción corporal se instituye como un asunto de ley y gobierno, porque esta diferencia no tenía que prolongarse con la crianza, tal como ocurría en la Atenas contemporánea a Platón; por el contrario, algunas, las guerreras y filósofas, estarían eximidas del cuidado de la prole, al menos del cuidado individual. El estado se haría cargo de las criaturas nacidas ${ }^{5}$, bien gestadas y bien nacidas, dado que el gobernante cuidaría de que la gestante tuviese una vida higiénica, centrada fundamentalmente en la gimnasia. La identidad de las funciones de los varones y las mujeres exige que la procreación sea el primer acto político, dado que los cuerpos de los varones y de las mujeres están presentes de igual manera en el centro de la ciudad (Canto, 1994). La diferencia derivada de la procreación, única diferencia entre varones y mujeres e insignificante para acceder a la sabiduría y al gobierno, a juicio de Platón, pasa a ser la primera preocupación de la organización de la ciudad en República (459 e- 461 e) hasta el punto de que el gobernante convierte a las mujeres más excelentes en una especie de útero común al servicio del estado para seleccionar los mejores nacimientos (González, 1999: 148).

\section{EN CUERPO Y ALMA ${ }^{6}$}

No hay ninguna diferencia entre varón y mujer para el gobierno, decía Platón en el libro V de República. La única diferencia es la de que el varón engendra y la mujer pare, tal como hemos visto más arriba. Única diferencia, si atendemos al gobierno, pero si atendemos a la reproducción es una diferencia importante. En el caso de Platón, era el Estado el encargado de todo lo relativo a la reproducción. Platón para borrar las diferencias entre engendrar y gestar, por un lado, y parir, por el otro, desvincula tales procesos de la familia y los convierte en asuntos políticos.

Esta diferencia que Platón declara irrelevante, y desplaza sus consecuencias al estado, cobra nuevo sentido a la luz del desarrollo de las tecnologías reproductivas, especialmente en el caso de la subrogación de la maternidad o alquiler de vientres, pues el cuerpo de las mujeres puede convertirse a ser una auténtica fábrica de cuerpos $^{7}$, productor de criaturas y óvulos.

\footnotetext{
${ }^{5}$ Hay que tener en cuenta que a estos centros serían llevadas nodrizas que serían las propias madres, pero que en ningún caso sabrían quienes eran sus hijos (República 460 c-d).

${ }^{6}$ Expresión utilizada por Zsuzsa Berend en “The Romance of Surrogancy”.

${ }^{7}$ The mother machine (La máquina madre) es el título del libro de Gena Corea (1985).
} 
Esta práctica reproductiva está desplazando a la adopción debido a las ventajas que ofrece a los futuros padres sobre esta: más barata, más rápida y con carga genética propia, al menos la mitad, correspondiente al varón para el caso de parejas heterosexuales cuyos óvulos no sean aptos, varones solos o parejas de varones.

La mayoría de los países no permiten la gestación subrogada, pero, sin embargo, existen vericuetos legales, no exentos de contratiempos -que de vez en cuando aparecen en la prensa- ${ }^{8}$, para que quienes buscan este método de tener hijas o hijos, subrogen la gestación en países donde sí está permitida y, una vez que nace, se inscriba con la nacionalidad de sus padres y vuelva con ellos su país con los papeles "en regla”. Lugares de traslado para parejas cuyos países no permiten tal técnica, son India, Estados Unidos, Méjico, Georgia y Kazakistán, Chequia, Ucrania y Grecia ${ }^{9}$. De todos ellos el país más pujante en maternidad subrogada es India a donde las parejas que no son muy poderosas económicamente, viajan para dejar los espermatozoides, también dejar o buscar óvulos en el caso de que los de la mujer no puedan ser fecundados, de que sea una pareja de varones, o un varón solo, para que sean fecundados in vitro y transferidos posteriormente a la que los va a gestar. En muchos casos los partos son múltiples, debido a la implantación de varios embriones para asegurar el nacimiento de al menos uno.

Los dos países de referencia para España, donde, como dijimos, tal práctica está prohibida, son Estados Unidos y la India; esta última se está imponiendo como lugar de referencia para personas procedentes de países en los que -como en el caso de Españano está admitida tal práctica reproductiva. Las razones para la elección de la India son que los costes son significativamente inferiores a los de Estados Unidos, hay buenos doctores, habla inglesa y un gobierno que se esfuerza para que la India sea un país de destino de turismo reproductivo (Bailey, 2011). Además, el tiempo de la subrogación o contrato de gestación, es mucho más corto que el de adopción: unos once meses frente a unos cuantos años de la adopción. El precio del alquiler de un vientre oscila, según los países, entre los 35.000 y más de 100.000 euros, el de una adopción internacional unos 26.000 euros. La contratación de la gestación es más cara y más rápida. Desde que empiezan los trámites hasta el nacimiento pueden transcurrir unos once meses ${ }^{10}$.

Beauvoir y Firestone veían la maternidad y el embarazo como uno de los pilares de la sumisión de las mujeres. La primera dice: "Con frecuencia no parece maravilloso, sino más bien horrible que un cuerpo parásito prolifere dentro del propio cuerpo; la

${ }^{8}$ Ver en Asturias24 (18-02-2015) el relato de una pareja de varones homosexuales que después de cinco años, todavía no tienen todos los trámites en regla.

${ }^{9}$ Cada país tiene sus propias reglas de elección de los contratantes: personas solteras, parejas heterosexuales, parejas homosexuales: Grecia se ha incorporado en 2014 para parejas heterosexuales y mujeres solteras. Aunque no está prohibido para varones solteros, ni parejas homosexuales, al no haber regulación explícita, no está garantizado que no surjan posteriores problemas legales.

${ }^{10}$ Asturias24 (15-02-2015). 
mera idea de esa monstruosa hinchazón la atemoriza.... Es presa de imágenes de hinchazón, desgarramiento, hemorragia” (Beauvoir, 1987:274).

La segunda en Dialéctica de la sexualidad enuncia la causa de la opresión de las mujeres e identificada esta, que no es otra que la maternidad, vislumbra la liberación, una vez que la maternidad se desate de la naturaleza y, por ende, de las mujeres. La maternidad tecnológica traerá de suyo la neutralización del principal lastre biológico que arrastramos las mujeres.

¿Qué entendía Firestone por "liberarse de la maternidad”? Abogaba por una placenta artificial y criticaba a quienes desarrollaban estas investigaciones más para salvar prematuros que para desarrollar todo el proceso de gestación (Firestone1976: $247)^{11}$.

Los avances que se han desarrollado en las tecnologías reproductivas desde finales del siglo XX no han proporcionado la anhelada placenta artificial de Firestone, sino que han encontrado placentas naturales dispuestas: se trata de la gestación por sustitución, maternidad subrogada, contrato de gestación o vientres de alquiler. Diferentes modos de nombrar el mismo hecho, pero que cada uno esconde una valoración del mismo ${ }^{12}$.

Con esta técnica la gestación se consigue por medio del implante de embriones en la gestante contratada. Y, una vez que se confirma el embarazo, las emociones se implantan en los corazones de quienes contratan. El embrión se traslada del laboratorio al vientre de la gestante contratada a la vez que las emociones, tradicionalmente consideradas propias de la gestante, se instalan en la vida de la persona o personas contratantes: son éstas las que se entusiasman con la noticia del embarazo, las que ansían los informes de las sucesivas pruebas y ecografías; y, por fin, ven colmados sus deseos con el nacimiento ${ }^{13}$. La gestante permanece muda o casi. El embarazo biológico

\footnotetext{
${ }^{11}$ Ver Philip Ball, Contra natura. Sobre la idea de crear seres humanos (2012). Este autor nos ofrece una historia del alcance de intervención científica en el campo de la reproducción. Comienza el capítulo IX, que lleva por título Hágame otro con una cita del biotecnólogo Gregory Stock para quien "en un futuro no muy lejano se considerará una imprudencia tener hijos mediante concepción natural”. Ball en su repertorio de las nuevas formas de llegar a la vida humana cita al sexólogo australiano Norman Haire, quien, en una obra publicada en 1927, temía la probable llegada del día en el que se utilizasen animales para gestar humanos; y nos recuerda que la concepción interespecies ya es un hecho, pues se han gestado íbices en cabras. Menciona, asimismo, las investigaciones sobre úteros mecánicos como las del japonés Yosinori Kumabara quien logró mantener con vida unos fetos de cabra durante tres semanas en placentas artificiales.

${ }^{12}$ Quienes defienden la práctica abogan por la primera denominación, porque la segunda parece poner en conflicto maternidades, mientras que la tercera revela un "mercantilismo" de la maternidad, que no parecen con disposición de aceptar.

${ }^{13}$ Asturias24, (15/02/2015) el entrevistado recuerda que él y su pareja habían asistido al penúltimo test de esfuerzo --una prueba para comprobar el estado fetal--. "Uno de los niños no paraba de moverse", indica. A la salida, ambos posan con las manos apoyadas sobre la barriga 
ha de ser presimbólico, meramente natural o mecánico, no ha de tener ninguna parafernalia de apego, sentimiento..., mientras que la parte contratante, sea varón o mujer es la que recrea la emoción de la maternidad y/o paternidad. La embarazada contratada sabe y se comporta como tal: que el feto no es suyo ${ }^{14}$. En el caso de las subrogadas estadounidenses, las emociones también afectan a la gestante, pero no hacia lo gestado, sino hacia la pareja para la que gesta, lo que ha sido interpretado (Berend, 2012) como una estrategia de ocultar el mercantilismo. Cuando la subrogación es de mujeres pobres, no se oculta la necesidad de dinero como motivo de subrogación (Bailey, 2011).

Podemos decir que hay dos modelos de relaciones entre las partes de un contrato de gestación: el americano (Berend 2012) y el indio (Bailey 2011) o, quizá sea más exacto, aquel en el que la subrogada es de clase media y en el que la subrogada es de clase baja y vive en la miseria. En el americano en muchos casos se desarrolla una especie de romance entre la "pareja infértil" (también pude ser una persona sola, podemos decir la "persona infértil") y la gestante, hasta el punto de que cuando los "infértiles dejan enfriar o enfrían deliberadamente la relación, la gestante sufre una especie de sentimiento negativo de desamparo, abandono o traición (Berend, 2012). Según el análisis de Zsuzsa Berend, lo que prevalece en la subrogación, more estadounidense o clase media, es el "acto de amor" de la gestante hacia la pareja o el amor de la pareja hacia ella, relación que silencia la parte comercial y contractual. La subrogada no tiene sentimientos maternales en absoluto, sino que tiene un profundo sentido de obligación y solidaridad para con la pareja contratante. Contrato en el que se involucró, no para ganar dinero, esto sería secundario, sino para colaborar en la satisfacción de deseos tan fuertes y legítimos como son los de tener descendencia, así, es una tarea en la que deposita "cada gramo del corazón, del alma y de la vida”. Los sentimientos maternales hacia el feto son experimentados por la pareja contratante. La gestante no puede ser maternal hacia una hija o hijo que van a ser donados. Tampoco es, en la percepción construida por las agencias, una mera "madre desnaturalizada". La gestante comprende la "fuerza" del impulso de ser madre y se sacrifica para complacer ese deseo considerado tan arrollador como legítimo. Así, las agencias enfatizan la relación de la subrogación con un "acto de amor" y promueven grupos donde se vertebran las experiencias alrededor de esta idea para fortalecerse mutuamente comparando las experiencias. En internet uno de los reclamos publicitarios es "regala vida”. Existe, según Berend, todo un lenguaje amoroso desde el principio de la relación entre la gestante y los futuros padres desde el momento en que se describen las sensaciones iniciales como "amor a primera vista" seguido de largas conversaciones telefónicas donde "se habla de todo". Subrogadas y padres-madres contratantes ${ }^{15}$ hablan del "milagro del encuentro". La mayoría de las subrogadas tienen entre tres y cuatro hijos quienes junto con su marido apoyan la decisión y se involucran en una

de la gestante. Una enfermera inmortaliza el momento en una fotografía. Fue justo entonces cuando rompió aguas (el parto se adelantó). "Estuve presente en el parto. Todo fue muy bien, muy emocionante" (entrevista a una pareja de varones que adoptaron en Estados Unidos)

${ }^{14}$ Ibíd.

15 También denominados intencionales. 
especie de romance entre familias, que parece durar más en la subrogada que en los llamados "padres intencionales", pues todo el cúmulo de flechazos que llevan a la relación singular, con frecuencia se torna despecho para la subrogada, si una vez concluido el embarazo y conseguida la criatura, la pareja se distancia con la hija o hijo conseguido. Algunas subrogadas lo aceptan con escepticismo como uno de los episodios de la relación amorosa: el sufrimiento. No es el bebé lo que añoran, sino la relación con los padres del bebé, con la familia que han contribuido a formar. Desilusión generada por reinterpretar la relación como empleo, como un asunto de negocios y no como un asunto de amor, tal como había sido elaborado desde la entrada en contacto hasta el parto. Es la subrogada quien vive la relación como intercambio de emociones, mientras que los contratantes definen el vínculo más como un asunto de negocios que como un intercambio emocional. La subrogada se suele sentir usada y reinterpreta con dolor retrospectivamente la relación como un contrato o negocio que antes había pensado como una relación singular y no meramente mercantil (Berend, 2012).

Esta construcción emocional de agencias no es universal, antes bien, cuando las contratadas son mujeres pobres, como en la mayoría de los contratos de la India ${ }^{16}$, no es el amor lo que sustenta la maternidad subrogada, sino la necesidad. La necesidad de dinero es tan acuciante que no se deja esconder detrás del romance. Aquí una mujer percibe por un embarazo lo que ganaría diez años en un trabajo agrícola, "nosotras les damos el bebé y ellos nos dan el dinero que tanto necesitamos. Es bueno para ambas partes” (Bailey, 2011). Se necesita el dinero para tener una casa, para pagar una operación a un hijo, para elevar la dote de la hija, para montar un negocio, en fin, es una de las oportunidades para "emprender".

El negocio en la India comenzó en 2004 y desde los inicios se presentó como una actividad cada vez más floreciente económicamente. La clínica pionera fue la de Akanksha en Anand, lugar que recibe el apodo de "la cuna del mundo". Tanto la donante de óvulos, caso de que sea necesaria, como la subrogada han de pasar una selección de características físicas: altura de más de 1.60, piel lo más clara posible y entre 50 y $60 \mathrm{Kg}$. de peso; también se tiene en cuenta la casta, la religión y el atractivo físico. Además ha de tener un período regular, hijos ${ }^{17}$, ser emocionalmente estable, no consumir tabaco ni alcohol y no tener infecciones de transmisión sexual.

Existen importantes diferencias (Bailey, 2011) entre la asistencia sanitaria que recibe una mujer en la India según si está embarazada "para otro" o "para ella”. En el caso de que la gestación sea para la gestante, tanto la vida de la madre como la del nacido tienen altas tasas de mortalidad, pero si es por subrogación, hay un exhaustivo control de la embarazada que en algunos casos, cuando proviene de lugares muy pobres, permanece durante todo el embarazo en la clínica a fin de controlar y regular

\footnotetext{
${ }^{16}$ En 1991 el primer ministro de la India, Narasimba Rao, prometió abrir las puertas al mercado exterior (García, 2009:172).

${ }^{17}$ La existencia de hijos es una garantía de fertilidad.
} 
milimétricamente su vida en aras del buen nacimiento. Tienen las gestantes asegurada, por tanto, la asistencia si el hijo no es para ellas, pero en el caso de que lo sea, tienen muchas posibilidades de morir o de que se muera la criatura. Recientemente el gobierno prometió realizar cuatro revisiones por embarazo, pero en realidad son pocos los casos en los que se hace. Bailey también señala el triste historial reproductivo de la India a mediados del siglo XX cuando el gobierno emprendió la planificación familiar estatal y pocos años más tarde la esterilización era una práctica médica habitual, la mayoría de las veces en condiciones higiénicas y médicas lamentables.

El aumento de los contratos de gestación en la India está relacionado con la redistribución del trabajo en la era de la globalización (Federici, 2013: 120) que está "volcando las tareas de reproducción sobre las espaldas ${ }^{18}$ de las mujeres del tercer mundo". Señala esta autora que, por un lado

"El desarrollo de un vasto mercado infantil de alcance internacional, organizado mediante sistemas de adopción, y que ha evolucionado en un negocio que mueve millones de dólares. Hacia finales de los años ochenta, se calculaba que cada cuarenta y ocho minutos un niño adoptado entraba en Estados Unidos, y a comienzos de la década de 1990, solo desde Corea del Sur se exportaron 5.700 niños anuales a EEUU”.

Por el otro,

"Hemos podido ver el crecimiento de "granjas de bebés", en las que específicamente se producen niños para su exportación, y el empleo creciente de "mujeres del Tercer Mundo" como madres de alquiler. La subrogación materna, como la adopción, permiten a las mujeres de los “avanzados” países capitalistas evitar la interrupción de sus carreras o hacer peligrar su salud por tener un hijo. En contraposición, los gobiernos del "Tercer Mundo" se benefician del hecho de que cada niño vendido trae divisa extranjera a sus arcas; y el Banco Mundial y el FMI aprueban tácitamente esa práctica puesto que la venta de niños sirve para corregir el "exceso demográfico” y armoniza con el principio por el cual las naciones deudoras deben exportar todos los recursos naturales, de los bosques a los seres humanos" (Federici, 2013:120). ${ }^{19}$

${ }^{18}$ En este caso sería más atinado decir “sobre los vientres”.

${ }^{19}$ La imagen que nos dibuja Federici si bien podemos considerarla ajustada en lo que se respecta a la adopción, turismo sexual y matrimonios por “catálogo”, no así en lo relativo a la maternidad subrogada. En esta no son solo las mujeres de países ricos quienes contratan por no interrumpir su carrera, también mujeres que no pueden gestar y varones (que tampoco pueden). La elección del país depende de las posibilidades económicas de los contratantes y de las 
La subrogación es una parte del mercado y los tráficos que potencia la globalización ante la Nueva División Internacional del Trabajo. Y dentro de los tráficos con el que más se relaciona la subrogación es con el de la prostitución (Federici 2009: 121). Se hace eco Federici del análisis de Janice Raymond (1989) quien da cuenta de que en 1988 tuvo lugar en Nueva York un congreso sobre el tráfico de mujeres en el que se dedicó un apartado para las mujeres utilizadas en procesos de subrogación. La autora llama la atención sobre el hecho de incluir esta compra-venta dentro del tráfico de mujeres, frente a la prevención más habitual que es la de sospechar de tráfico de niños y niñas. Los argumentos liberales a favor de la subrogación coinciden con los de a favor de la prostitución: una mujer adulta puede elegir y hacer con su cuerpo lo que le venga en gana, ya que su cuerpo es suyo. Podríamos añadir que desde perspectivas liberales la subrogación puede ser incluida en los derechos sexuales y reproductivos: cada quien puede utilizar todos los medios a su alcance para tener una hija o hijo. Pero estos argumentos liberales suponen, según Janice Raymond (1989), apuntalar la servidumbre reproductiva de las mujeres en nombre de la libertad de las propias mujeres. Recordando a Orwell "la libertad es esclavitud" o, podemos añadir, "la servidumbre voluntaria" de la Boètie. La subrogación, según manifiesta esta autora, aumenta en los países más pobres, esto es, se va deslocalizando, y, como tal, se va abaratando, eliminando posibles críticas: cuanto más barato, más accesible, más practicado y menos cuestionado. La expansión en estos países más baratos y "tranquilos" va a depender de las redes de prostitución establecidas.

Así, continúa Raymond, en Bangkok hay 700.000 mujeres dedicadas a la prostitución de las que 30.000 tienen menos de dieciséis años; en Corea del Sur hay 1 millón sobre 41 millones de personas. La explicación de por qué hay tantas prostitutas radica en que han sido reclutadas por los militares americanos y por el turismo sexual de occidente y Japón y por las agencias de los matrimonios por catálogo. Esta compraventa masiva de sexo de las mujeres es el caldo para la subrogación. Muchas mujeres prostituidas cuando pierden atractivo y relumbrón para el sexo, son útiles para el embarazo. La autora aporta ejemplos de cuán cerca están el tráfico de mujeres y el de niñas y niños. Así, en Corea hay mujeres que anualmente van con un niño o niña a las agencias de adopción y después de recibir un dinero se despiden hasta el año próximo, o en Sri Lanka donde hay "granjas de niños" en las que mujeres embarazadas son separadas de sus hijos una vez que dan a luz y en algunos casos son obligadas a tener coito con turistas europeos para que los niños sean más europeos que asiáticos.

"El liberalismo reproductivo de EEUU engendra un nuevo tráfico de mujeres alrededor del mundo subsidiario de la llamada libertad reproductiva que contrata mujeres para servir de incubadora [...] una nueva versión de la maternidad como trabajo pagado y [...] una nueva imagen de la mujer feliz de servir a otros”. (Raymond 1989).

garantías jurídicas que ofrezca el país de destino para la tramitación de la inscripción de la criatura en el país de los padres. 
Para Raymond, la subrogación está conectada con la prostitución, la prostitución con los puntos de vista liberales occidentales de la sexualidad y reproducción, el liberalismo con el imperialismo, el imperialismo con al militarización, la militarización con la disponibilidad de las mujeres, especialmente la de los países del tercer mundo para la prostitución... Sería despojar a las mujeres de la dignidad, dignidad que ha de estar antes que los derechos. La subrogación solo puede ser defendida como un derecho, derecho reproductivo en un contexto liberal que es ciego para la dignidad (Raymond 1989). No hay ninguna posibilidad de corregir mediante un contrato la tremenda desigualdad que supone la subrogación. Para Raymond el contrato de subrogación es ilegítimo por indigno.

Ahora bien ¿cabría pensar situaciones en las que un contrato de subrogación no tenga la objeción de la explotación y/o la opresión de las mujeres gestantes? Nos acercaremos a esta cuestión siguiendo a Tamar Pitch (2003: 38-39) quien plantea este dilema al hilo de los argumentos de Shalev, por un lado, y Pateman, por el otro.

La diferencia entre Pateman y Shalev radica en que para Pateman el cuerpo es un elemento importante de la constitución de la subjetividad, mientras que para Shalev la subjetividad se constituye sin el cuerpo. Para Pateman, la mujer se sitúa respecto a la maternidad de modo distinto a como se sitúa el varón respecto a la paternidad, mientras que para Shalev esta diferente situación puede ser borrada por la tecnología, al igual que en el caso de Platón era borrada por la política. La diferencia entre ambas radica en considerar el cuerpo como elemento de la constitución del yo: ¿cuerpos diferentes, subjetividades diferentes?

Las posturas antagónicas entre Shalev y Pateman son sintetizadas por Pitch del siguiente modo:

"Shalev considera que la autonomía reconocida y promovida por el contrato procede precisamente de la posibilidad de separar el cuerpo (instrumento de la reproducción) de las emociones, el cuerpo de la implicación psíquica. Pateman, al contrario, encuentra en el contrato la forma paradigmática de la compraventa de la sujeción y la obediencia, entendiendo con esto la imposibilidad de separar el "cuerpo" de la "mente". Lo que diferencia a los varones de las mujeres en esta compraventa es que el contrato en el que participan las mujeres implica siempre el acceso a su sexualidad [...]. Las mujeres “venden”, resultando sometidas, la esfera entera de la sexualidad y la reproducción, emociones, fantasías, energías psíquicas entendidas naturalmente” (Pitch, 2003: 67$68)$.

Para Shalev, jurista israelí, las tecnologías de la reproducción liberan, al menos potencialmente, a las mujeres de los vínculos que las hacen diferentes de los varones, esto es, las propias capacidades reproductivas; así, las mujeres, gracias a las técnicas reproductivas, pueden separarse de su cuerpo y de los impedimentos que derivan de tales capacidades y les impiden llegar a ser seres individuales de pleno derecho. La mujer, nos viene a decir Shalev, se libera así del lastre que la liga a la naturaleza y que 
le impide su plena igualdad con el varón; de este modo se constituye en sujeto autónomo y calculador que evalúa costes y beneficios, pudiendo suscribir, en consecuencia, un contrato de arrendamiento de útero. Para esta autora el contrato de subrogación no solo es una necesidad, sino una bondad, esto es, es una forma de que constituir nuevos espacios de libertad para las mujeres.

“[El contrato de subrogación] promueve y legitima el deseo femenino de autonomía. El movimiento histórico que va del estatus al contrato, sostiene Shalev, no tiene por qué pararse en el umbral de la reproducción. Este movimiento [...] es susceptible de romper los últimos y más fundamentales vínculos que hacen posible que las mujeres estén sujetas a un régimen patriarcal” (Pitch, 2003: 31-32).

Toda la tecnociencia referida a la gestación que va desde la anticoncepción a la subrogación posibilita caminos de libertad que van desde la libertad negativa a la libertad positiva: desde la libertad a no concebir a la libertad a concebir como se desee: (Pitch, 2003: 32). Tal contrato de subrogación, para Shalev, sería el último peldaño de las mujeres para ingresar en la cultura y desprenderse de la naturaleza que le impone la gestación.

Cabe hacer una primera objeción a la argumentación de Shalev: la gestación no está desvinculada de las mujeres: se transfiere a otra mujer. Algunas mujeres pueden ser madres sin gestación, pero la gestación no puede ser, al menos de momento, sin mujeres.

Las tecnologías reproductivas, a juicio de Shalev, introducen nuevos modelos de convivencia, pues hacen de la reproducción ““"un proyecto de cooperación” que puede tener como resultado una relación de progenitores alejada de vínculos biológicos”20 . Y en este alejamiento de los vínculos biológicos no cabe conservar como irreductible la gestación; en el proceso de generación no cabe introducir variables legales en función del sexo, no ha de haber diferenciación entre sexos; no es legítimo situar el embarazo como situación "particularmente emotiva" que justifique no considerar válida una subrogación ante la imprevisión de los sentimientos “maternales” de la gestante. Estas precauciones jurídicas le parecen a Shalev reminiscencias biologicistas de "la fuerza del útero”. Así, para esta autora, estarían en paridad legislativa la inseminación por donante y la maternidad subrogada. Son la misma técnica para solucionar la esterilidad o ausencia de varón, en el primer caso, y la esterilidad o ausencia de mujer en el segundo caso. El sexo estéril es quien se tiene que "duplicar" entre biológico y social. Si hay esterilidad masculina hay padre biológico y social. Si la hay femenina, hay madre biológica y social. No ver estas esterilidades como equivalentes es fruto, según

${ }^{20}$ Argumento similar al que había dado Firestone (1976: 258 y ss.), quien esperaba que la liberación de las mujeres de la maternidad acabaría también con las enfermizas relaciones de la familia "biológica". Otro campo de estudio es el proceso de asimilación de los hijos e hijas de sus orígenes cuando estos son contractuales. 
Shalev (1992: 89 en Pitch, 2003: 33) de concebir a las mujeres y a la reproducción según los esquemas patriarcales que atribuyen a la maternidad el último bastión de una peculiar naturaleza biológica de la mujer. Aunque Shalev no lo confía todo a la tecnología, dado que esta puede constituirse como un sistema de control del proceso reproductivo, ve en ella la oportunidad de liberación del resto biológico que perdura en la diferenciación de los sexos. La mujer, a su juicio, no puede seguir siendo prisionera de su útero, y sacralizar la gestación, de manera que la maternidad se constituya como diferente a la paternidad, solo porque esta última no tiene la experiencia de la gestación. Maternidad y paternidad son procesos idénticos legalmente, aunque biológicamente no lo sean. La ley puede corregir los errores de la naturaleza, nos indica Shalev.

En las antípodas de este planteamiento nos sitúa Pitch a Pateman, politóloga australiana, para quien el contrato no es la expresión de la libertad, sino la constitución de la desigualdad y la subordinación. El contrato social habría sustituido el patriarcado clásico por el moderno ${ }^{21}$. Ahora el contrato de subrogación introduce modificaciones en el patriarcado moderno en cuanto abre una puerta para la reaparición del patriarcado clásico que se apoya en el derecho del padre (1995: 288 y ss.). Según Pateman, en el contrato de subrogación es el futuro padre, heterosexual, no la pareja, quien pacta; de modo que se invierte la relación natural, pues ya no es la madre la que da un hijo o hija al padre, sino al revés: "el contrato de subrogación permite a al varón presentarle a su esposa el último regalo: un niño” (Pateman, 1995:295) ${ }^{22}$. Una primera objeción a la interpretación de Pateman descansa en la experiencia de en algunos casos son mujeres de élite quienes pactan que otra mujer geste para ellas, no por imposibilidad física, sino por conveniencias de otro tipo, además de parejas de heterosexuales cuya mujer no puede gestar y de varones homosexuales. Ni en el caso de las parejas homosexuales varones, ni en el de la mujer que pudiendo gestar no lo hace, se cumple que el varón da un hijo de regalo a la mujer. Para Pateman (1995:316) un orden social libre requiere límites y la autonomía sería, precisamente marcar esos límites.

Tampoco admiten el contrato de subrogación feministas como Kelly Oliver (1989), quien desde una perspectiva marxista califica el contrato de gestación como enajenado y alienado, y, si bien admite que desde la óptica marxista todos los contratos de trabajo lo son, sin embargo, es el único trabajo desde la esclavitud donde la gente no solo vende los productos de su cuerpo, sino también las "funciones corporales" durante el período de embarazo. En línea con Andrea Dworkin, que duda de la libertad atribuida a las subrogadas, compara la lentitud de los estados para conceder libertades a

${ }^{21}$ Ver El contrato sexual. Distingue entre el patriarcado clásico, predemocrático, donde el poder descansa en la autoridad del padre y el patriarcado moderno contractual apoyado en el contrato social que oculta un contrato sexual por el que las mujeres no forman parte de ese contrato.

${ }^{22}$ Hemos de tener en cuenta que Pateman escribe esto en 1988. Todavía era reciente el conocimiento mundial respecto la maternidad subrogada a través del largo litigio conocido con el nombre del bebé $\mathrm{M}$. donde la diversas sentencias a partir de la negativa de la subrogada a entregar al bebé, acabaron dándoselo a la pareja contratante. 
las mujeres con la prontitud para darles libertad para vender, en este caso la gestación. Estados como la India donde la venta de la gestación es el púlpito para defender la libertad, mientras se niega a las niñas la educación, las mujeres han de mantener el honor de la familia, se les niega el aborto, en definitiva, parece que el gobierno hindú solo ve a las mujeres libres para pactar la gestación.

Para Oliver la defensa liberal del contrato no es sostenible, porque esconde diferencias de clase y de género. Si hubiese igualdad, el contrato no existiría. Frente a la defensa liberal que sostiene que nada hay de malo en que personas adultas con capacidad de autodeterminación pacten intercambiar lo que cada una de ellas necesita: unos niños y otras dinero, Oliver califica a la subrogación como la quintaesencia del trabajo enajenado.

Argumenta que hay algunas diferencias entre otros trabajos y el de subrogación aplicando a la subrogación los cuatro estadios de la alienación propuestos por Marx en el análisis del trabajo. En primer lugar, la enajenación lo es del producto producido, en este caso el "producto" es el cuerpo del niño creado a partir del cuerpo de la gestante. No es, como decía Marx una transformación de la naturaleza exterior, es un producto de la naturaleza interior. En segundo lugar, la enajenación afecta al trabajador y al proceso de producción. El trabajador se convierte en un apéndice de la máquina. Aquí la trabajadora se convierte ella misma en máquina
“A diferencia de otros trabajadores, no es un apéndice de una máquina, es una máquina. Su cuerpo llega a ser la maquinaria de producción sobre la que el contratante tiene el control último. A pesar del esquema liberal que sostiene lo contrario, ella no tiene iguales derechos que el contratante" (Oliver 1989).

En tercer lugar, la subrogación es un trabajo doblemente enajenado, precisamente porque no hay separación entre trabajo y ocio: todo es trabajo en el sentido de que el tiempo que dura el embarazo, más los anteriores tratamientos para llegar a él, la embarazada ha de comer, pasear, beber, descansar, conforme a los dictados del personal médico encargado de supervisarla. Si Marx había dicho que los humanos se sienten libres cuando desarrollan actividades que comparten con los animales y esclavos cuando realizan lo que se supone es propio de humanos; en este tipo de trabajo, tanto ocio como trabajo es animal ${ }^{23}$. La subrogada no solo está enajenada en

${ }^{23}$ Hay que tener en cuenta que esta característica de la no separación tiempo de trabajo y tiempo de ocio es una de las características del trabajo en la globalización. Hay quienes, como Negri y Hardt lo definen como trabajo inmaterial fruto del desarrollo de las nuevas tecnologías de la comunicación y hay quienes, como Federici, lo describen como las conscientes nuevas formas del empresario para generar más beneficios. Que una parte de este trabajo material se denomine trabajo afectivo no es más que una eufemística denominación para una realidad laboral acelerada, estresada, atemorizada, como "la experiencia gastronómica en la que una camarera tenía que cumplir 25 puntos de la "secuencia del servicio”” (Federici, 2003:198). La cuestión 
su humanidad, cuando desarrolla un trabajo, sino también en su animalidad: comer, beber, pasear, tener relaciones sexuales no es algo que pueda hacer libremente, porque eso precisamente es lo que ha contratado y es lo que ha de ser vigilado, "no solo está enajenada de su potencial como ser humano (...) sino también de los placeres animales [...] La subrogada se siente [...] siempre como un animal. Incluso su producción humana es solo reproducción animal”. La subrogada contrata lo único que dejaba libre el capitalismo: la animalidad. Así, ya no le queda nada libre, ergo, deviene esclava.

En cuarto lugar, el trabajador está enajenado respecto a otras personas. En el caso de la subrogación hace que los niños sean vistos como mercancías y las mujeres como productoras de esas mercancías. Además, los niños mismos se verán como mercancías.

Oliver, por otro lado, critica aquellas feministas que quieren ampliar los análisis de Marx a la reproducción. Precisamente la analogía entre producción y reproducción puede llegar a producir el efecto contrario que la teoría feminista pretende: en vez de controlar un medio de producción, convertir a las mujeres en meros medios de producción.

Las tecnologías de la reproducción, sobre manera la subrogación, ponen en fuga a aquellas emociones que encadenan amor-sexualidad-reproducción. Estas prácticas reproductivas serían del gusto, si se nos permite el anacronismo, del filósofo medieval Agustín de Hipona, pues coinciden con su descripción de la sexualidad edénica, la de antes del pecado original, donde nada se escapaba a la voluntad. De no ser por el pecado original (Ciudad de Dios (XIV, 23-24) “el hombre habría vertido el semen y al mujer lo habría recogido en sus genitales cuando y cuanto fuese necesario, gracias al dictado de la voluntad y no por excitación de la libido”.

Cualquier cosa, como en el Edén, menos libido sexual es lo que hay en la reproducción tecnológica en general y más en la modalidad de maternidad por gestación sustitutoria donde la madre gestante y parturienta no experimenta, o al menos no ha de experimentar, ninguna de las emociones habitualmente atribuidas a las embarazadas y parturientas como sentir el cuerpo del bebé, ver su figura en las ecografías y toda una serie de emociones que habitualmente en nuestra sociedad se exteriorizan alrededor de la maternidad. Frente a lo simbólico de la maternidad, tenemos una proliferación paródica de maternidad y de paternidad.

El asunto de las nuevas tecnologías de la reproducción tiene innumerables perspectivas: nuevas connotaciones de qué es un padre o una madre, definiciones varias según legislaciones, virtualidades emancipadoras...., en fin,... una de ellas es la nueva forma de ganarse la vida de muchas mujeres como donadoras de óvulos y como gestantes. Podemos decir que la venta o donación de semen por parte de los varones es asunto antiguo, así como su conservación; más reciente es la donación de óvulos y su conservación. Hace pocos años que se garantiza la congelación de óvulos y no es lo

sería si estamos animalizando el trabajo o humanizando el ocio. Federici parece defender lo segundo y criticar a Negri y Hardt por defender lo primero. 
mismo donar semen que óvulos, en el sentido de las mismas molestias. La donación de óvulos requiere un proceso previo que es la estimulación ovárica que implica cierto peligro físico, porque tal estimulación depende de un aumento hormonal que entraña ciertos riesgos. Además, la extracción ha de hacerse en un quirófano y con anestesia. La venta de óvulos, traspasados ciertos límites puede incluso poner en peligro la vida de la mujer. La maternidad subrogada exige en la mayoría de las legislaciones que el óvulo no pertenezca a la gestante para así eliminar todo vínculo biológico entre gestante y nacido, para que sea un "mero horno" de cocción o "tierra" de cultivo y no pueda reclamar en base a una filiación genética, caso de que el óvulo fuese de la gestante.

Volviendo a la discusión entre Pateman y Shalev recogida por Pitch (2003), podemos plantearnos la legitimidad del contrato pensando qué grado de legitimidad damos los contratos de gestación. Si en el análisis marxista el proletario tiene en exclusiva su fuerza de trabajo, a las mujeres pobres les quedaría su fuerza gestante. Esta actividad sería el paradigma del modelo de trabajo en la época de la globalización, donde no se diferencia entre trabajo-empleo y no trabajo. Tiempo de trabajo y tiempo de ocio están entretejidos tan cuidadosamente que son difíciles de distinguir. Porque, como en el caso de la gestación para otro u otra, la regulación de la vida de la gestante es la garantía, aunque nunca es posible asegurar el éxito totalmente, de que el resultado sea bueno: de que la niña o el niño sea del agrado de quien o quienes contrataron.

El cuerpo de la gestante hasta el parto está totalmente a disposición de los contratantes: en ningún momento se puede olvidar de su función, debe cuidarse con esmero para que la gestación sea saludable. También podemos ver este trabajo como una nueva versión de "chica interna”, en el sentido de estar totalmente a disposición de las eventualidades de una familia, si bien en la modalidad de interna ella ingresa en una familia, aquí ocurre a la inversa: una familia en forma de espermatozoides y óvulo ingresa en ella, en su cuerpo. Es este el trabajo inmaterial y emocional de la era de la globalización que socializa las tareas de cuidado e incluye entre estas la gestación subrogada como versión perversa del "hijo deseado" que como todo deseo, debe de ser satisfecho, siempre que previamente pueda ser pagado.

Necesitamos una propuesta, argumenta Pitch (2008: 72-73), que medie entre quienes, como Pateman mantiene una estructura fuerte del derecho y débil de las mujeres y de Shalev que mantiene un principio de autonomía universal, abstracto y velado. Pitch propone partir de una noción de autonomía diferente: una autonomía en proceso, entendiendo que nos vamos elaborando según aquello que somos y también que decidimos; de ahí que podamos elaborar contratos, o por lo menos determinados tipos de contratos de manera que los términos del contrato no pueden determinarse "de una vez para siempre”, sino que lleve incorporados plazos que permitan su revocación.

\section{SI UNA CONCLUSIÓN FUESE POSIBLE}

La reivindicación de que la biología no decidiese el destino fue un lugar común de reivindicación del feminismo de la igualdad desde la década de los setenta del siglo $\mathrm{XX}$. Asentada esta demanda, la globalización y tecnología nos sirve la respuesta en 
forma dispar: se puede ser madre sin pasar por la gestación, por un lado, y se puede pasar por la gestación sin ser madre, por el otro. Esta situación ya es tan antigua como la adopción, donde una criatura en desamparo es criada por otras personas, pero la novedad estriba en que con la subrogación, con el contrato de gestación, estamos abriendo nuevas formas de ganarse la vida para satisfacer deseos de "infértiles" que descansan en la capacidad, exclusiva por ahora, de gestar de las mujeres. Y estas formas de ganarse la vida no están lejos de la esclavitud, al menos en las condiciones en que se hace en determinados países.

La Organización Mundial de la Salud cambió en 1947 la definición de salud. De ausencia de enfermedad como se venía entendiendo, llegó a ser "estado completo de bienestar físico, mental y social”. La salud así definida no entra en el campo de las necesidades, sino que se amplia al de los deseos. El paciente pasa a ser usuario y consumidor (García, 2014). De algún modo, el deseo y el dinero están regulando prácticas que no tienen que ver con la ausencia de enfermedad, sino con el "completo bienestar físico, mental y social”. Y en la consecución de tal estado de bienestar, muchas mujeres se están convirtiendo en una especie de úteros transparentes para los que el observador privilegiado es quien paga, porque es quien decide.

Recogemos la propuesta de Pitch (2008: 73) quien encuentra un término medio entre la prohibición y el contrato liberal, en la elaboración de una teoría del contrato que descanse en una concepción del sujeto como proyecto, de manera que los términos del contrato de subrogación contemplen algo así como una ley de plazos en los que la contratada pueda ir decidiendo, por ejemplo, si sigue adelante con el embarazo o no, si una vez nacido lo entrega o no.

Como bien dice Cèlia Amorós (2014: 38), la maternidad humana, ha de ser una maternidad pensada, esto es, no solo según el cuerpo sino también según el alma, como diría Platón, desde el momento en que la mujer tiene que aceptarla. Esta afirmación que hasta ahora suscribíamos para los debates en torno al aborto, deberíamos ampliarla al debate a la maternidad subrogada.

Platón para salvar la justicia eliminó la familia en las clases superiores y subrogó la gestación de las mejores, previo emparejamiento con los mejores. En la actualidad para salvar la familia, eliminamos la justicia y así la pareja o persona "infértil” tiene la posibilidad de pactar la gestación con otra mujer, que en muchos casos está en situación de extrema necesidad, que gestará para entregar la criatura a quienes han contratado la gestación. La posibilidad de opciones en el proceso reproductivo y de diferentes personas que pueden concurrir para cumplir el deseo de tener descendencia, nos lleva a un proceso que es la gestación y a una parte del cuerpo que es el útero. Útero que los antiguos identificaban con la tierra, Filmer con vasija, y ahora los estados y empresas con negocio. 


\section{REFERENCIAS BIBLIOGRÁFICAS}

AMORÓS, CÈLIA (2014): Salomón no era sabio, Madrid: Editorial Fundamentos.

ARISTÓFANES: Las Asambleístas (1986), Barcelona: Boch (introducción, traducción y notas de Antonio López Eire).

ARISTÓFANES: Lisístrata (1981), Madrid: Editora Nacional (traducción de F. Rodríguez Adrados).

BALL, PHILIP (2013 [2012]): Contra natura. Sobre la idea de crear seres humanos, Madrid: Turner, (traducción de Víctor V. Úbeda).

BAILEY, ALISON (2011): Reconceivind Surrogacy: Toward a Reproductive Justicie Account of Indian Surrogacy, Hypatia, vol. 26, n 4, fall, 715-741.

BEAUVOIR, SIMONE (1987 [1949]: El Segundo sexo, Tomo II, La experiencia vivida, Buenos Aires: Ediciones Siglo XX, (traducción de Pablo Palant).

BECKMAN, LINDA y HARVEY, MARIE (2005): Current Reproductive Technologies: Increased Access and Choice? Journal of Social Issues, Vol.61, No. 1, 1-20.

BEREND, ZSUZSA (2012): The Romance of Surrogacy, Sociological Forum, vol. 27, No 4, pp. 913-136.

CANTO, MONIQUE (1993): The Politics of Women's Bodies: Reflections on Plato en Tuana, Nancy (ed.), Feminist Interpretations of Plato, pp. 49-85, Pennsylvania: The Pennsylvania State University Press.

CLARK, KENNETH (1981 [1956]): El desnudo. Un estudio de la forma ideal. Madrid: Alianza Forma (versión española de Francisco Torres Oliver).

FEDERICI, SILVIA (2013 [2012]: Revolución en punto cero. Trabajo deméstico, reproducción y luchas feministas, Madrid: traficantes de sueños (traducción de Carlos Fernández y Paula Martín).

FIRESTONE, SHULAMITH (1976 [1973): Dialéctica del sexo, Barcelona: Kairós (traducción Ramón Ribé Queralt)

GARCÍA, ANA (2009): Historia de las mujeres en la India, Barcelona: Laertes.

GARCÍA, SILVIA: La regulación tecnológica del dualismo sexual y el diseño de cuerpos normativos, en Cartografías del cuerpo. Biopolíticas de la ciencia y la tecnología (Eulalia Perez Sedeño y Esther Ortega Arjonilla (eds.)), pp.469-519.

GIMENO, BEATRIZ (2011): Vientres de alquiler: no es tan sencillo. Revista Transversales $\quad \mathrm{n}^{\circ} 2, \quad$ junio. http://www.nodo50.org/trasversales/t22bgvda.htm

GONZÁLEZ, AMALIA (1999): La conceptualización de lo femenino en Platón, Madrid: Ediciones Clásicas. 
GOODMAN, ELLEN "Úteros (2008): S.A." www.sinpermiso.info/textos/index.php?id=1822 (consultado el 17 de diciembre de 2014).

MONTEROS, SILVINA (2014): Maternidad subrogada: no es tan sencillo descartarla como posibilidad, Afin, $\mathrm{n}^{\circ}$ 66, noviembre de 2014, pp. 1-15. Disponible en internet ddd.uab.cat/pub/afin/afinSPA/afin_a2014m11n66iSPA.pdf (consultado el 7 del 4 de 2015).

IBARRA, DIANA (2011): ¿Es Aristóteles al sexo como Platón es al género?, Devenires XII, 24, 108-127.

ILLOZ, EVA (2007): Intimidades congeladas: las emociones en el capitalismo, Barcelona: Katz Editores.

IRIARTE, ANA y GONZÁLEZ, MARTA (2008): Entre Ares y Afrodita, Madrid: Adaba Editores.

OLIVER, KELLY (1989): Marxism and Surrogacy, Hypatia, Autumn, pp. 95-115.

PATEMAN, CAROLE (1995 [1988]): El contrato sexual, Barcelona: Anthropos (traducción de María Luisa Femenías y revisión de María Xosé Agra)

PANITCH, VIDA (2013): Global surrogacy: exploitation to empowerment, Journal of Global Ethics, vol 9, No. 3, 329-343.

PITCH, TAMAR ( 2003 [1998]): Un Derecho para dos: La construcción jurídica de género, sexo y sexualidad, Madrid: Trotta (traducción de Cristina García Pascual).

PLATÓN: Diálogos, Tomo III (1986): Fedón, Banquete, Fedro, Madrid: Gredos (introducciones, traducciones y notas de Carlos García Gual (Fedón), M. Martínez Hernández (Banquete) y Emilio Lledó (Fedro).

PLATÓN: Diálogos, Tomo IV (1986): República, Madrid: Gredos (introducciones, traducciones y notas de Conrado Eggers Lan).

RAYMOND, JANICE (1989): The international traffic in women: women used in systems of surrogacy and reproduction. Reproductive and Genitc Engeneering, Vol. 2, No. 1, pp. 51-57.

ZAMORA, JESÚS (1998): Úteros de alquiler, Isegoría, vol. 18, 205-212.

ZERILLI, LINDA (1996): Un proceso sin sujeto: Simone de Beauvoir y Julia Kristeva, sobre la maternidad. En Silvia Tubert (ed.) Figuras de la madre, pp. 155-188. 